\title{
Stabilizing Research Departments in a 10\% World
}

\author{
John F. Leslie, Head, Department of Plant Pathology, Kansas State University
}

$\mathrm{L}$ and Grant universities have a long history of a trifold mission of teaching, research and outreach (extension) in the agricultural and mechanical arts. The form of this mission has evolved over the 150+ year history of these institutions as the number of people involved directly in production agriculture has dwindled since the early 1900s and rural populations have decreased accordingly. Different departments and specialty areas within the university have changed as have the expectations of faculty.

For faculty, the most significant change in expectation has been that those in STEM-related disciplines are expected to obtain and maintain extramural funding for research programs. This funding may come from a variety of public sources - usually federal or state government - or private, usually grower groups, commercial companies or foundations. This expectation has become larger with time, starting as a minor component in the early 1900s when John Wesley Powell first made the case for government support of research as we know it through the US Geological Survey. After World War II, this change became even more profound as the amount of money directed to publicly funded research, primarily through the Federal government, increased rapidly.

More senior attendees of this meeting probably can recall times when individual investigator grants above the $50^{\text {th }}$ percentile in a federal grant panel stood a good chance of being funded. Such expansion encouraged many students to pursue careers in STEM disciplines, and often as academics. At that time, many scientists at the state Agricultural Experiment Stations (AESs), who also usually were faculty at the state's land grant institution, were not usually heavily involved in the quest for external funding because there were sufficient funds to support their research efforts through the AES. Research funds from USDA for additional projects usually came with a lower reimbursement for indirect cost expenses than did funds from other federal agencies such as NSF, NIH, USDA, DOE and USAID, but there were sufficient institutional resources to cover the costs associated with proposal preparation and grant administration.

Since a high water mark in the 1960s, however, the overall funding trend line has been downward. For agricultural scientists, this change has meant that research funds from their AES are primarily tied up in salaries, often only faculty salaries, and that conducting a viable research program required external funding. As states have reduced funding for higher education, AES funding usually has declined as well, but unlike universities who can increase tuition to increase 
funds available, AESs have been faced with massive funding reductions that have necessitated changes in mission and their approach and view of external funds. State-associated budget reductions often are presented as across-theboard budget reductions, departments often lose a faculty position that is vacant due to retirement or resignation. Such losses are effectively strategic cuts that leave a department unable to do all that it could previously since the specialization of most faculty members is not usually duplicated within a department. Maintaining core capabilities and addressing new areas in a field are particularly difficult under such circumstances.

\section{The Value of Research}

Research lives a bit of a schizoid life. In some ways research is the absolute king on campus. Research outputs - both quality and quantity - are used as measures for institutional quality and measures of scholarly activity more often than just about anything else. Grant funds (preferably from a federal source that pays full overhead), $h$-factors and various citation impact statistics, amongst others, dominate discussions of institutional quality. Becoming a member of the US National Academy of Sciences can be a bit like striking gold for a faculty member in terms of the offers they may receive from institutions looking for a means to increase their standing in ranking systems. Indirect costs associated with externally funded research, although rarely recovered in toto, are critical components of many institutional budgets and often enable scholarly or other activities in areas that are not closely related to the research project that generated them. Thus, reductions in funding for STEM-related research can crimp budgets in many areas across campus.

From another perspective, research is more a stepchild or royal bastard than the king/queen of the castle. State budget cuts are often distributed across the board, but in a manner that protects the instructional component of a university's activities. Internal services take many of these hits, with research support, especially in technical staff, infrastructure and equipment maintenance, usually hit hard as well. As budgets become more heavily driven by tuition these problems increase as questions often are raised about the propriety of using tuition funds for anything other than the direct support of the teaching mission. Then there is the public misperception of faculty as working only when they are standing in front of class, with research considered to be a hobby or a "spare" time activity. In the face of this combination of factors it is little surprise that academic administrators often choose research activities for cuts when there are no good budget choices available to them and something has to go.

The recent decrease in the availability of federal funds for research has pushed both of these perspectives to even greater extremes. Those who can win consistently in a world where the funding success rate is $10 \%$, or less, become more valuable as faculty and more vulnerable to poaching by competitors. As the research enterprise becomes more costly to fund in terms of both money and public relations, its presence on many campuses decreases and these institutions become (or revert to) primarily tertiary teaching 
institutions rather than research universities. In so doing student and public exposure to the research enterprise is reduced and the way of thinking that underlies the research process is limited to professional practitioners rather than permeating society for the benefit of all.

\section{Faculty Success}

No one at a university can succeed if the faculty are not successful. Defining success is a bit like defining "better", it depends on where you are and where you are trying to go. In some instances success is the best teaching evaluation scores possible, while in others success requires maximizing the appropriate research indicator(s). Most commonly some combination of the two extremes is the desired goal with additions for service and outreach required as well. At many research universities in STEM disciplines, tenure expectations include the receipt of a nationally competitive (usually federal) grant, and the graduation of a Ph.D. student in addition to high profile scholarly publications and perhaps the placement of a postdoctoral colleague in a significant permanent position. Newly hired faculty may also be required to do extensive committee and other service work and to teach large introductory classes on a regular basis.

The $10 \%$ world is having a significant impact on these expectations. The reduction in federal funding often costs universities faculty positions as research and indirect cost revenue streams shrink. Hiring a new faculty member to replace someone who has left or retired is not automatic and newly hired faculty are often treasured. In my department we often minimize service work until after a tenure decision has been made and try to keep teaching loads as light as possible, to enable more research to be done.

Issues of students, grant funding, and publications are often entangled. External funds are needed to continue projects beyond the initial start-up period. In a $10 \%$ world, obtaining these funds is increasingly difficult. Is the expectation that all STEM Assistant Professors are capable of landing a major federal grant realistic, when success rates are at or below $10 \%$ ?

More established faculty also are having great difficulties. Yet if there is no money, how can a new faculty member demonstrate that they have enough ideas and capabilities for a sustainable 25+ year career? Acquiring additional teaching duties is the traditional price for not acquiring reliable external funding in a STEM discipline, but the current contraction is too severe for simply increasing teaching duties for a few unsuccessful mid-career faculty to suffice as a solution. What obligations do institutions have to faculty who are hired with a significant research output expectation?

In a $10 \%$ world our standard assumptions and expectations are failing to serve us either individually or institutionally. Many responses, e.g., hiring researchers on non-tenure-track lines or hiring faculty whose sole job is to teach, are philosophically and intellectually unsettling or unacceptable given the values of free speech within the Academy and the expectation for faculty to be continuously searching for new knowledge through cutting edge research. If we need to reduce the number of faculty to meet 
the $10 \%$ world's harsh economic demands, how should we do it? Will we end up with a series of elite institutions where most research is done? Or will we instead end up with some elite institutions and a number of very good and excellent research units at other locations where they are effectively orphans. Can we afford the balkanization that results from such egalitarian dispersion? Or should we instead be thinking about ways in which excellence is concentrated at a relatively few locations and be altering the missions of departments, colleges and institutions to these new realities?

\section{Departments}

The center of academic life for a faculty member is the department to which they belong. Departments provide an environment within which faculty members work, but are not usually an entity that one works "for". Departments are the entities most commonly evaluated in comparisons of different universities, and their performance often is tracked as individual entities. They are the heart of academic communities and the comparisons of them with family units is not at all out of place. Look at the lengths to which most departments will go to avoid not tenuring an Assistant Professor when the time comes. A former Dean told me that seeing even a single "no" vote, beyond the curmudgeons who could never vote "yes", was a cause for worry because it was so much more difficult to vote "no" than it was to vote "yes".

Keeping departments healthy and happy, not just functional, requires a sense of common purpose and a togetherness that is both practical and personal. Faculty in a well-functioning department can survive many of the vagaries of a $10 \%$ world because they have a vision for where they want to go and have identified potential means to get there, both individually and collectively. They are capable of independent work and capable of being team members. Departments have cultures that are a product of the people who populate them.

Non-faculty staff often are important bits of "glue" that keep things together as others come and go. In effective departments they "own" a bit of the department just as much as a faculty member would. In a $10 \%$ world this diverse ownership and ability to work in teams (or as a team) provides the resilience needed to survive and continue to thrive. Leaders for departments are numerous, with senior faculty often the largest cohort. Formal leadership also comes from a peer (Chair or Head), who commonly has little, if any, formal leadership or management training. Such a "professional amateur" needs significant patience and buy-in to be successful and a willingness to go along and get along to keep a top-ranked department functioning at its maximum abilities.

\section{Continuing Department Head Fears and Whines}

Department Heads are the middle management of an academic institution, but unlike their industrial counterparts more desire to go back down to the faculty level than to progress up the administrative ladder. Few are trained for the job and even fewer had being Department Head as a career goal. Most serve out of a sense of duty to their colleagues, their department or their institution. 
These reluctant leaders are now thrown into a $10 \%$ world in which static or declining budgets at the department level are the norm. The valuation an institution puts on a department is often difficult to discern - until the bottom falls out because a stellar faculty member leaves for greener pastures or departmental stalwarts retire and someone must pick up the essential duties that they had flawlessly an selflessly performed for years.

The safety nets currently available to Department Heads might suffice to hold small objects dropped from a few feet above them if the object hits the net instead of a hole. Ripping the net or hitting the hole can degrade a department's capacity almost overnight. For example, major equipment can cost hundreds of thousands if not millions of dollars to replace or repair, with departments often on the hook for all or much of the expense. Loss of a major grant can leave a stellar research group in tatters. Technicians and postdocs scramble for alternatives that allow them and their families to continue to live indoors and eat regularly while graduate students struggle to find ways to finish nearly completed research programs and avoid the pain and loss of time that comes with identifying a new advisor and research project.

Hiring and evaluating faculty also brings unanticipated tensions. The criteria for success of a new Assistant Professor often has changed little, even though the external resources required for such success are more difficult to obtain. Making the top $10 \%$ cut in any field as an Assistant Professor is an admirable feat that is all but expected in most STEM disci- plines given current funding levels. Anticipating not only whether a job candidate is likely to be funded but also whether they will be a long term fit with other faculty in the department requires careful vetting, hard questions and broadly strategic thinking on the part of all who are involved in the hiring process.

Finally, with the limited resources available, rewarding those who have done excellent work and are deserving of recognition financially and otherwise is difficult. Telling a faculty member that their performance is "average" may be true, but most faculty have been in the upper portion of every evaluation they have experienced since they were in primary school. If there are 12 people in a department with four Nobel prize winners and four more National Academy of Science members there are probably several very good faculty members who are receiving at best average and more likely below average performance reviews. In a $10 \%$ world these highly qualified individuals would be primary targets for other institutions to lure away, potentially leaving a stellar department with a dismal future in terms of younger faculty to serve as replacements for their more senior colleagues. Open market negotiations for top faculty are common at all institutions. In a $10 \%$ world these negotiations become even more critical as only the very best faculty are likely to be funded continuously and provide the core support needed for the institution's research enterprise to succeed.

\section{Interdisciplinary Efforts}

Departments serve as the fundamental blocks on which the institution rests, 
but aspersions about academics being in silos, insulated from the rest of the world abound. The suggested cure for these issues is interdisciplinary centers wherein individuals from various backgrounds and diverse fields of expertise are hired to focus on a common problem. In some cases new buildings are built and faculty are moved from their current departments to a different physical location, while in others, the center is a "virtual" one whose members are physically dispersed on campus but have occasion to get together on a regular, usually at least weekly, schedule.

These efforts can be productive when they work as envisioned, and can provide a means to build teams that are competitive for large multi-PI grants that can be a critical part of the survival strategy in a $10 \%$ world. Yet for productive research departments there are often down sides. These departments are often already interdisciplinary in nature with various faculty approaching a broad common problem from multiple directions. Collaborations that range across the basic-applied spectrum occur more naturally in such departments, since those involved are often at different stages of a common research pipeline, rather than trying to tie multiple pipelines together to give a novel output. Successful departments also have identifiable areas of strength in which multiple faculty combine their skills to attack common problems as a team, in much the way envisioned for interdisciplinary centers.

Interdisciplinary centers, if not carefully implemented, can disrupt highly functional departments. For example, siphoning off faculty with expertise in a particular part of a field, e.g. genetics, to work with others from different departments who have similar expertise but in a different department, can lead to the effective creation of a new department under the guise of creating a center. In so doing the best faculty from several different departments may be brought together and in the process devastate the departments they were in with their effective departures leaving programmatic holes that cannot readily be patched.

If faculty that belong to an interdisciplinary center have a tenure home in a department, then the problem of having two masters arises. Both the department and the center claim the faculty member, with the center providing a research home (and perhaps even research support) and the department providing a tenure and disciplinary home. Both have expectations as the faculty member should be contributing to both. Should the faculty member leave, then the question of whose faculty position it really is - center or department - can lead to major disputes. Successfully developing and implementing a center without diminishing its contributing departments is far from a trivial task.

Then there are questions such as does the center have the academic standing of a department, and can it offer courses and degrees under its own name or only under the name of the departments in which its faculty are tenured? For faculty, the simple manner of determining who conducts annual performance evaluations and the standards against which performance is evaluated can be crucial to job satisfaction and productivity. In the long run, the critical 
question is whether the new resources available and the unique intellectual atmosphere that lives within the center justifies the trouble and care that it takes to manage it. Interdisciplinary centers may help some faculty survive in the 10\% world, but they are neither a panacea nor a cure all for currently limited external funding.

\section{An Obvious Vision and Associated} Advice

In a $10 \%$ world the obvious vision is that we are all in this together and must collectively find a way to survive. This message needs to reverberate within departments and centers, but it needs repetition from the administration all the way up to the level of the governing board. Communication must be clear, frequent and never in just a single direction. Writing is common as are speeches and presentations, but one-on-one communication and communication across administrative levels are essential as well. In many cases this type of communication carries with it implied congratulations for a job well done. Why would a President, Provost or Dean spend their time with faculty, staff or students who are not delivering something of great value to their institution? Senior leadership also should model efforts to explore alternatives for getting things done so that everyone else knows that such efforts are both expected and supported.

Collaboration becomes the key to implement the vision. Collaboration in any and every possible form is essential to maximize local areas of strength and to enable extensive participation in the core areas of institutional competency. Maintaining recognizable core and specialized competencies for which the institution has an outstanding reputation provides firm positions to which other programs can be tethered until circumstances change and enable growth and expansion.

Stakeholders from alumni to students to faculty and staff and university friends need to be able to own successes and to work together using their varied strengths and skills to advance the institution and its critical programs. Developing the institution as a "destination" requires a change in attitude, and a kind, but firm, resolve to build areas of strength to their highest possible level while ensuring that all programs are competitive and of at least "average" quality. Faculty are notorious for acting independently and for functioning as "Lone Rangers" when it comes to promoting their programs. Such independence may have been necessary to obtain a Ph.D. in the first place, but it can hamper the efforts to form suitable teams that can address the big picture problems for which funding often is available.

Stabilizing and institutionalizing departmental cultures so people cooperate because they want to rather than because they have to, makes collaboration easier for everyone. Working with your friends is almost always more fun than working with your colleagues, unless the two groups are more or less the same. A 10\% world presents stresses, but the stressors are more readily weathered if they are confronted by a group that can work and play well together.

\section{Changes for a $10 \%$ Era}

The first fact to recognize in the $10 \%$ era is that survival until times get better 
is critical. Yet mere survival of everything and everyone is not a very inspiring goal. The $10 \%$ era is one in which relatively strict winnowing occurs as the academic enterprise is forced through a bottleneck of restricted funding. Getting through the bottleneck with style and grace refines skills and reinforces alliances that are necessary for success once the winnowing is complete. Astute academic management during the winnowing process can lead to a major shuffling and rearranging of priorities and academic strengths within and between institutions. Style and grace change the perceptions of what is occurring and provides another reason for stakeholders to buy into the change process.

Partnerships in a $10 \%$ world need to become symbiotic relationships in which both partners can anticipate the other's needs and desires. Both administration and faculty share the goal of their institution being widely recognized and respected, and of providing important services and information for stakeholders, often on a global basis. Fiscal decisions, especially those where budgets are cut, need to be made with unremitting focus on their implications. Losses of positions, whether through strategic or across-theboard cuts, almost always lead to a strategic loss, whether intended or not. Having a sense of where we want to go provides a different lens to use when viewing a series of less-than desirable options.

\section{Conclusions on a $10 \%$ Era}

The current fiscal crisis that is engulfing university research is leading to major rethinking of the value of research. With funds for research more difficult to attain, the value of research is being questioned. In spite of the efforts and thought being put towards obtaining research funds from foundations, companies and other private sources, there is no effective alternative to government funding for the research enterprise that has developed since the end of World War II.

The possibility that the country's research enterprise may be reduced during this $10 \%$ era is quite real and faculty and administrators must work together to ensure that the embers that ignite research activity survive the current fiscal quenching. Without a vision for an institution's role in research, such efforts are hampered and detrimental strategic decisions may be made unknowingly. Collaborative efforts have become all but essential to obtain the external funds upon which most research programs rely. These collaborative efforts may result from departmental or interdisciplinary interactions depending on the nature of the question being asked. Enabling these efforts is probably the single most important thing that can be done to ensure the survival of research activities through this $10 \%$ era.

\section{Acknowledgment:}

This is Manuscript no. 15-218-A from the Kansas Agricultural Experiment Station, Manhattan. 